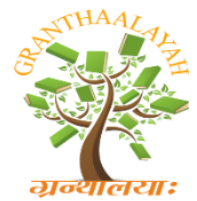

INTERNATIONAL JOURNAL OF RESEARCH GRANTHAALAYAH A knowledge Repository

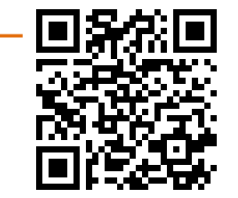

Science

\title{
EFFECT OF EXCESSIVE GESTATIONAL WEIGHT GAIN ON PREGNANCY OUTCOME: A CASE STUDY OF TERTIARY HOSPITALS IN BENUE STATE, NIGERIA
}

\author{
Amarachi B. Nwaogwugwu ${ }^{1}$, Dr. Nwabueze Achunam Simeon ${ }^{2}$, Dr. Celestine E Ekwuluo ${ }^{3}$ \\ 1,2 Nnamdi Azikiwe University Awka, Nigeria \\ ${ }^{3}$ Family Health International (FHI 360), Nigeria
}

\begin{abstract}
Motivation/Background: Little is known of adverse pregnancy outcomes resulting from Excess Gestational Weight Gain (EGWG) in Benue state, Nigeria. In this study, we aimed to assess the effects and association of EGWG on pregnancy outcome in tertiary hospitals in Benue State.

Method: We used retrospective cohort study to examine the data obtained from the general Antenatal Care (ANC) Register of 350 pregnant women who attended ANC clinic between January 1, 2016 and December 31, 2016. Pre-pregnancy Body Mass Index (BMI) was calculated by dividing weight in kilograms within first 14 weeks of gestation by square of height in meters while total gestational weight was calculated as difference between weight before, or at 14 weeks and weight at 37 weeks of gestation prior to delivery.

Results: Data analysis was done using SPSS version 21. Out of the sampled folders, 103 (29.4\%) women gained excess weight during pregnancy, $130(37.1 \%)$ women gained the recommended weight while $117(33.4 \%)$ women gained weight less than the recommended value. Analysis showed strong association between EGWG and pregnancy induced hypertension/pre-eclampsia, caesarean section and macrosomia.

Conclusions: The study concluded that EGWG should be avoided by educating women on the need to gain appropriate weight during pregnancy to prevent adverse pregnancy outcomes which affect both mothers and their offspring.

Keywords: Caesarean Section (CS); Eclampsia; Preeclampsia; Pregnancy Induced Hypertension (PIH); Stillbirth; Gestational Diabetes; Macrosomia.

Cite This Article: Amarachi B. Nwaogwugwu, Dr. Nwabueze Achunam Simeon, and Dr. Celestine E Ekwuluo. (2020). "EFFECT OF EXCESSIVE GESTATIONAL WEIGHT GAIN ON PREGNANCY OUTCOME: A CASE STUDY OF TERTIARY HOSPITALS IN BENUE STATE, NIGERIA." International Journal of Research - Granthaalayah, 8(3), 180-189. https://doi.org/10.29121/granthaalayah.v8.i3.2020.141.
\end{abstract}




\section{Introduction}

Excess Gestational Weight Gain (EGWG) is a public health issue known as the amount of weight gained by pregnant woman in excess of the recommended weight gain for various categories of Body Mass Index (BMI). Excess weight gained before and during pregnancy is a significant public health concern in Nigeria. The effects include risk of gestational diabetes, pregnancy induced hypertensive disorders, macrosomic babies, caesarean section delivery and in some circumstances still-birth. ${ }^{1-5}$ The increasing trend of EGWG is of great concern since it is directly linked to maternal disability adjusted life years, morbidity and mortality of the mother and/or the baby. The institute of medicine (IOM) guideline published in 2009 categorized acceptable weight gain during pregnancy differently for women depending on their pre-pregnancy body mass index (BMI) only and not dependent on age, race, ethnicity, parity and smoking history. ${ }^{6}$ BMI ranges are divided into underweight $\left(<18.5 \mathrm{~kg} / \mathrm{m}^{2}\right)$, normal weight $\left(18.5-24.9 \mathrm{~kg} / \mathrm{m}^{2}\right)$, overweight $\left(25-29.9 \mathrm{~kg} / \mathrm{m}^{2}\right)$ and obese $\left(\geq 30 \mathrm{~kg} / \mathrm{m}^{2}\right){ }^{7}$ Women who were underweight prior to pregnancy are recommended to gain weight between 12.5-18kg during gestation, those with acceptable BMI are expected to gain 11.5$16 \mathrm{~kg}$, while overweight and obese women should gain $7-11.5 \mathrm{~kg}$ and $5-9 \mathrm{~kg}$ respectively. ${ }^{8}$

Furthermore, excess weight gained before and during pregnancy may increase the cost of obstetric care as a result of negative impacts it exposes mother and child to. Sequel to this, the reduction of the obstetric complications by preventing excess weight gain in pregnant women has far-reaching positive effect, contributing not only to a reduced maternal mortality, but also lead to the reduction in perinatal and neonatal mortality. While other causes of maternal mortality have received attention, little or nothing has been done in checking the impact of non-communicable diseases such as obesity and overweight on pregnancy outcomes in Nigeria. This study hence aligns with the sustainable development goals (SDGs) 3.1 and 3.2 towards reducing maternal mortality ratio and ending preventable deaths of newborn hence improving pregnancy outcomes in Nigeria.

\section{Aim}

To assess the effects of excessive gestational weight, gain on pregnancy outcome in tertiary hospitals in Benue State, Nigeria.

\section{Specific Objectives}

1) To determine the prevalence of excessive gestational weight gain among mothers in tertiary hospitals in Benue State.

2) To ascertain the effects of excessive gestational weight gains on maternal outcome in tertiary hospitals in Benue State.

3) To establish the effects of excessive gestational weight gains on fetal outcome in tertiary hospitals in Benue State.

\section{Materials and Methods}

The study was conducted in Federal Medical Center (FMC) Apir, and Benue State University Teaching Hospital (BSUTH) between January 1, 2016 and December 31, 2016. These two hospitals are the only tertiary hospitals in Benue State. Both hospitals have antenatal care clinic days with a monthly average patients 188 clients. Tertiary hospitals were selected as they have the technical know-how and facility to handle ranging outcomes of pregnancy, hence will have limited 
referral to other centres. The study utilized a retrospective cohort study. Folders of pregnant women who attended antenatal clinic and delivered singletons in any of the two hospitals between January 1, 2016 and December 31, 2016, irrespective of their age and marital status during the study period were included in the study. Women with pre-pregnancy diabetes mellitus, hypertension, multifetal births, or those who registered after 14 weeks of gestation, or had incomplete documentation during the ANC visits were excluded.

Sample size was calculated using the Lish-Kislie method. Prevalence of $30.6 \%{ }^{9}$ was used and confidence interval was set at $95 \%$, hence, 350 folders where included in the study. The inclusion criteria were pregnant women who attended antenatal clinic and delivered singletons in any of the two hospitals, irrespective of their age and marital status during the study period while the exclusion criteria include women with pre-pregnancy diabetes mellitus, women with prepregnancy hypertension, women who had multifetal births, women who registered after 14 weeks of gestation, women that had no weight measured at 37 weeks of gestation and women with incomplete documentation.

\section{Study Instrument and Data Management}

A proforma was designed to get the required data for this study. Contents of the proforma include; the women's ANC number, age, religion, tribe, occupation, weight $(\mathrm{Kg})$ within 14 weeks of gestation, and 37 weeks of gestation, history of gestational diabetes, PIH, pre-eclampsia and eclampsia. Other data collected include mode of delivery, baby's weight, macrosomic babies and stillbirth.

Pre-pregnancy BMI was calculated by dividing maternal weight in kilograms (kg) by the square of height in meters $(\mathrm{m})$ at the first antenatal visit within the first 14 weeks of pregnancy. Maternal weight within the first 14 weeks was taken as pre-pregnancy weight because a study by Fattah et al in 2010 observed that maternal weight does not change before 14 weeks of gestation. ${ }^{10}$ The prepregnancy BMI was categorized as underweight (BMI $<18.5 \mathrm{Kg} / \mathrm{m}^{2}$ ), normal weight (18.5-24.9 $\left.\mathrm{Kg} / \mathrm{m}^{2}\right)$, overweight $\left(25-29.9 \mathrm{Kg} / \mathrm{m}^{2}\right)$ and obese $\left(\mathrm{BMI} \geq 30 \mathrm{Kg} / \mathrm{m}^{2}\right)$ according to $2009 \mathrm{IOM}$ weight gain recommendation for pregnancy. ${ }^{8}$ Total gestational weight gain was calculated as subtraction of pre-pregnancy weight from the body weight at the end of pregnancy. ${ }^{11}$ In this study, body weight at the end of pregnancy was measured at 37 weeks of gestation prior to delivery.

\section{Statistical Analysis}

Data were analyzed with Statistical Package for Social Sciences software version 21. Descriptive statistics were used to describe the socio-demographic, anthropometric characteristics of respondents, the total gestational weight gained, and the respondent's pregnancy outcomes. ChiSquare $(\chi 2)$ was used to calculate the association between the following, age and pregnancy outcome, pre-pregnancy BMI and pregnancy outcome, pre-pregnancy BMI and total gestational weight gain, total gestational weight gain and pregnancy outcomes. P-value of $<0.05$ at $95 \%$ confidence interval (CI) was considered as statistically significant. Binary logistic regression was used to determine the odds ratio of the pregnancy outcomes in relation to age, BMI, and total gestational weight gain. 


\section{Results and Discussions}

\section{Socio-Demographic Characteristics of The Respondents}

Out of 1,780 (703 from BSUTH and 1,077 from FMC Apir, Makurdi) folders of women that delivered in the two tertiary hospitals from January 2016 to December 2016 were reviewed, 1,430 folders were excluded using the exclusion criteria. Hence 350 folders only were included in the study. From the aggregate data, mean age of women who were selected for this study was $28.26 \pm 4.75$ years. Socio-demographic characteristics including age range and tribe of the participants analyzed is detailed in table 1 below.

Table 1: Socio-Demographic Characteristics

\begin{tabular}{|c|c|c|}
\hline Variables & Frequency $(\mathbf{N}=\mathbf{3 5 0})$ & Percent \\
\hline Age (in years) & & \\
\hline$\leq 24$ & 77 & 22.0 \\
\hline $25-29$ & 140 & 40.0 \\
\hline $30-34$ & 96 & 27.4 \\
\hline$\geq 35$ & 37 & 10.6 \\
\hline Tribe & & \\
\hline Tiv & 183 & 52.3 \\
\hline Idoma & 56 & 16.0 \\
\hline Igbo & 32 & 9.1 \\
\hline Hausa & 18 & 5.1 \\
\hline Igede & 16 & 4.6 \\
\hline Others & 45 & 12.9 \\
\hline Occupation & & \\
\hline Traders & 76 & 21.7 \\
\hline Civil servant & 73 & 20.9 \\
\hline Artisans & 28 & 8.0 \\
\hline Unemployed & 173 & 49.5 \\
\hline
\end{tabular}

Key: Others under tribe: Etulo, Jukun, Igala, Yoruba, Etsako, Ibibio, Kukru (Liberia).

\section{Anthropometric Characteristics of The Respondents}

From the aggregate result, pre-pregnancy mean BMI stood at $25.99 \pm 5.12 \mathrm{~kg} / \mathrm{m}^{2}$ while mean weight gain of $10.24 \pm 4.11 \mathrm{~kg}$ was observed. Overall, roughly little above a $3^{\text {rd }}$ gained IOM recommended weight, little below a $3^{\text {rd }}$ gained excess of IOM recommended weight while a $3^{\text {rd }}$ gained less than the IOM recommended weight. This imply that 103 (29.4\%) of the respondents gained excess gestational weight while 247 (70.5\%) of the respondents did not gain excess gestational weight as detailed in table 2 .

Table 2: Anthropometric characteristics of respondents $(\mathrm{N}=350)$

\begin{tabular}{|c|c|c|}
\hline Variables & Frequency (n) & Percent \\
\hline Pre-pregnancy BMI (kg/m $\mathbf{2})$ & & \\
\hline Underweight & 19 & 5.4 \\
\hline Normal weight & 148 & 42.3 \\
\hline Overweight & 107 & 30.6 \\
\hline
\end{tabular}




\begin{tabular}{|c|c|c|}
\hline Obese & 76 & 21.7 \\
\hline Total gestational weight gain (kg) & & \\
\hline Gained less weight & 117 & 33.4 \\
\hline Gained recommended weight & 130 & 37.1 \\
\hline Gained excess weight & 103 & 29.4 \\
\hline
\end{tabular}

\section{Pregnancy Outcome of Respondents}

The result presented in table 3 below show that majority of the respondents had pregnancy complications and outcomes including caesarean section, followed by PIH then macrosomia. Less than 10 respondents had any of pre-eclampsia, gestational diabetes, eclampsia or stillbirth respectively.

Table 3: Pregnancy outcomes in respondents $(\mathrm{N}=350)$

\begin{tabular}{|l|c|c|}
\hline Pregnancy outcome & Frequency (n) & Percentage \\
\hline Caesarean Section & 79 & 22.6 \\
\hline Pregnancy induced hypertension & 44 & 12.6 \\
\hline Pre-eclampsia & 9 & 2.6 \\
\hline Gestational diabetes & 5 & 1.4 \\
\hline Eclampsia & 2 & 0.6 \\
\hline Macrosomia & 18 & 5.1 \\
\hline Stillbirth & 6 & 1.7 \\
\hline
\end{tabular}

\section{Association of Respondent's Pre-Pregnancy BMI With Pregnancy Outcomes}

Further analysis showed significant association between pre-pregnancy, table 4. Among the respondents that had PIH, majority were obese women $18(40.9 \%)$, followed by women that were overweight and normal weight. Similarly, caesarean section was performed on 30 (38.0\%) women with normal weight, followed by women who were obese women 22 (27.8\%), then overweight 25 (31.6\%) when compared to those that had and underweight $2(10.5 \%)$. Furthermore, slightly higher proportion of obese women had gestational diabetes $2(2.6 \%)$ when compared to those that had normal weight $3(2.0 \%)$. Among the women that had eclampsia, $3(33.3 \%)$ of them were obese while $5(55.6 \%)$ were overweight. Test of analysis significance an association between pregnancy induced hypertension and excess gestational weight gain as p-value gotten is $<0.5$. Detailed analysis is shown in table 4.

Table 4: Association of respondent's pre-pregnancy BMI and Pregnancy outcomes

\begin{tabular}{|c|c|c|c|c|c|c|c|}
\hline \multirow{2}{*}{$\begin{array}{l}\text { Pregnancy outcomes } \\
(\mathrm{N}=350)\end{array}$} & \multicolumn{3}{|c|}{ Pre-pregnancy BMI (Kg/m2) } & \multirow[t]{2}{*}{ Obese } & \multirow{2}{*}{$\begin{array}{c}\text { Fisher's } \\
\text { exact } \\
\text { test }\end{array}$} & \multirow[t]{2}{*}{ OR $(95 \% \mathrm{CI})$} & \multirow{2}{*}{$\begin{array}{c}\text { p- } \\
\text { value }\end{array}$} \\
\hline & $\begin{array}{l}\text { Under } \\
\text { weight }\end{array}$ & Normal & Over weight & & & & \\
\hline Caesarean Section $(n=79)$ & $2(2.5)$ & $30(38.0)$ & $25(31.6)$ & $22(27.8)$ & 3.83 & $1.32(0.99-1.76)$ & 0.28 \\
\hline $\mathrm{PIH}(\mathrm{n}=44)$ & $0(0.0)$ & $13(29.6)$ & $13(29.6)$ & $18(40.9)$ & 13.22 & $1.93(1.32-2.82)$ & $0.004 *$ \\
\hline Pre-eclampsia $(n=9)$ & $0(0.0)$ & $1(11.1)$ & $5(55.6)$ & $3(33.3)$ & 4.81 & $2.10(0.94-4.72)$ & 0.159 \\
\hline Gestational diabetes $(n=5)$ & $0(0.0)$ & $3(0.6)$ & $0(0.0)$ & $2(0.4)$ & 2.87 & $1.16(0.43-3.19)$ & 0.393 \\
\hline Eclampsia $(n=2)$ & $0(0.0)$ & $0(0.0)$ & $1(50.0)$ & $1(50.0)$ & 2.94 & $3.32(0.46-23.87)$ & 0.378 \\
\hline Macrosomia $(n=18)$ & $1(5.5)$ & $3(16.7)$ & $7(38.9)$ & $7(38.9)$ & 6.44 & $1.82(1.04-3.19)$ & 0.076 \\
\hline Stillbirth $(n=6)$ & $0(0.0)$ & $1(16.7)$ & $3(50.0)$ & $2(33.3)$ & 2.4 & $1.92(0.73-5.06)$ & 0.514 \\
\hline
\end{tabular}

Key: $*$ Statistically significant 


\section{Association Between Respondent's Pre-Pregnancy BMI \& Total Gestational Weight Gain}

From the aggregate analysis, total respondent's gestational weight gain showed that women who were had pre-pregnancy obesity and overweight gained higher proportion of weight during pregnancy as compared to women with pre-pregnancy normal weight and or were underweight. Cross tabulation and test of significance showed a significant relationship between pre-pregnancy BMI and total gestational weight gain as shown in table 5.

Table 5: Association between respondent's pre-pregnancy BMI and total gestational weight gain

\begin{tabular}{|c|c|c|c|c|c|}
\hline $\begin{array}{c}\text { Pre-pregnancy } \\
\text { Variables }\end{array}$ & $\begin{array}{c}\text { No GT excess } \\
\text { weight gained }\end{array}$ & $\begin{array}{c}\text { Excess GT } \\
\text { weight gained }\end{array}$ & $\begin{array}{c}\text { Fisher's } \\
\text { exact }\end{array}$ & OR (95\% CI) & P-value \\
\cline { 1 - 3 } Underweight & $17(89.5)$ & $2(10.5)$ & 54.1 & $2.82(2.08-3.83)$ & $<0.001^{*}$ \\
\cline { 1 - 3 } Normal weight & $131(88.5)$ & $17(11.5)$ & & & \\
\cline { 1 - 3 } Over weight & $64(59.8)$ & $43(40.2)$ & & & \\
\hline Obese & $35(46.1)$ & $41(53.9)$ & & & \\
\hline Overall & $247(70.5)$ & $103(29.4)$ & & & \\
\hline
\end{tabular}

Key: * Statistically significant

Recommended weight gain for various BMI (Underweight $=12.5-18 \mathrm{~kg}$; Normal weight $=11.5$ $16 \mathrm{~kg}$; Overweight = 7-11.5 kg; Obese $=5-9 \mathrm{~kg}$ )

\section{Respondents total gestational weight gain and pregnancy outcomes}

The study looked at the relationship between total gestational weight gain and pregnancy outcomes. Test analysis showed statistically significant association between pregnancy induced hypertension, macrosomia and excessive gestational weight gain as shown in table 6 . Association between gestational diabetes, eclampsia, stillbirth and excessive gestational weight gain were not statistically significant (table 6). Further analysis revealed that women who gained excess weight had higher chances of pregnancy outcomes including gestational diabetes $3(60.0 \%)$, PIH 32 (72.7\%), pre-eclampsia $8(88.9 \%)$, eclampsia $2(100 \%)$, caesarean section $44(55.7 \%)$ and macrosomic babies 16 (88.9) when compared to those who did not have excess gestational weight gain. (table 6). Detailed analysis is captured in table 6.

Table 6: Respondents total gestational weight gain and pregnancy outcomes

\begin{tabular}{|l|c|c|c|c|c|}
\hline \multirow{2}{*}{ Pregnancy outcomes } & \multicolumn{2}{|c|}{ BMI $(\mathbf{K g} / \mathbf{m} 2)$} & Fisher's & OR (95\% CI) & p-value \\
\cline { 2 - 5 } & $\begin{array}{c}\text { Excess } \\
\text { weight }(\%)\end{array}$ & $\begin{array}{c}\text { No excess } \\
\text { weight }(\%)\end{array}$ & $\begin{array}{c}\text { exact } \\
\text { test }\left(\boldsymbol{\chi}^{\mathbf{2}}\right)\end{array}$ & & \\
\hline Caesarean Section $(\mathrm{n}=79)$ & $44(55.7)$ & $35(44.3)$ & 33.9 & $4.52(2.66-7.67)$ & $<0.001^{*}$ \\
\hline PIH (n=44) & $32(72.7)$ & $12(27.3)$ & 45.43 & $8.83(4.32-18.04)$ & $<0.001^{*}$ \\
\hline Pre-eclampsia (n=9) & $8(88.9)$ & $1(11.1)$ & 15.73 & $20.72(2.56-167.87)$ & $<0.001^{*}$ \\
\hline Gestational diabetes $(\mathrm{n}=5)$ & $3(60.0)$ & $2(40.0)$ & 2.28 & $3.68(0.61-22.33)$ & 0.154 \\
\hline Eclampsia $(\mathrm{n}=2)$ & $2(100)$ & $0(0.0)$ & 4.82 & $3.20(0.000)$ & 0.086 \\
\hline Macrosomia $(\mathrm{n}=18)$ & $16(88.9)$ & $2(11.1)$ & 32.3 & $22.53(5.08-99.98)$ & $<0.001^{*}$ \\
\hline Stillbirth $(6)$ & $3(50.0)$ & $3(50.0)$ & 1.24 & $2.44(0.48-12.29)$ & 0.365 \\
\hline
\end{tabular}

Key: * Statistically significant 


\section{Discussion}

Excessive gestational weight gain with prevalence of $29.4 \%$ of in Benue state is considered one of the public health issues common in Benue state, Nigeria. Although weight gain may be seen as healthy lifestyle, adverse effects following excessive weight gain in pregnancy may lead to various obstetric complications. Equally, it is known that overweight and obesity are associated with some adverse health consequences such as heart disease, hyperlipidemia, hypertension, hypercholesterolemia, type II diabetes, and mortality. ${ }^{12}$ The study established prevalence of $29.4 \%$ excess pregnancy weight gain and an increased risk of Pregnancy Induced Hypertension (PIH), preeclampsia, and Caesarean Section (CS) in women with excess pregnancy weight gain. This finding aligns with the work of Halle-Ekane et al in 2015 with prevalence rate of $30.6 \% .^{9}$ and by Arora et al in 2013 with prevalence rate of 33.1\%. ${ }^{13}$ The result of this study also shows that those that gained excess weight are about 9 times more likely to have Pregnancy Induce Hypertension, 23 times more likely to have macrosomic baby and about 21 times more likely to have preeclampsia when compared to those without excess weight.

Various studies support the result from this study which shows that there were associations between excess gestational weight gain and Pregnancy Induced Hypertension including the by Zhou et al in 2015, ${ }^{14}$ which showed that women with excess gestational weight gain had Hypertensive disorders in Pregnancy (PIH and preeclampsia). It also supports the work of Li et al in $2013^{15}$ and Mochhoury et al in $2013^{16}$ which showed there was significant relationship between excess gestational weight gain and pregnancy induced hypertension. Equally, Halle-Ekane et al in $2015^{9}$ showed association between EGWG, pre-eclampsia and eclampsia. A study by Mbu et al in $2013^{17}$ at the Yaounde central hospital maternity, Cameroon, conducted from 2009 to 2012 showed significant association between EGWG and preeclampsia.

Furthermore, this study reveals a significant association between excess gestational weight gain and caesarean section. The result aligns with Chung et al in $2012,{ }^{18}$ which revealed that the rate of caesarean section in labour was significantly higher in women with high GWG compared to those with normal GWG. However, the study by Halle-Ekane et al in $2015^{9}$ did not show any significant association between excess gestational weight gain and caesarean section with $(\mathrm{p}=0.98)$. Furthermore, there was no significant association between excess gestational weight gain and gestational diabetes $(\mathrm{p}=0.154)$ and align with the study by Halle-Ekane et al in $2015^{9}(\mathrm{p}=0.36)$. However, in contrast with the study carried out by Halle-Ekane, ${ }^{9}$ Hedderson in $2010^{19}$ revealed an association between excess gestational weight gain and gestational diabetes.

With regards to fetal outcome and maternal excess gestational weight gain, the study showed that $29.4 \%$ (103) women that gained weight in excess of recommended weight were at greater risk of macrosomia, $(\mathrm{p}<0.001 \mathrm{OR}=22.53,95 \% \mathrm{CI}=5.08-99.98)$. This study result aligns with Halle-Ekane et al in $2015,{ }^{9}(\mathrm{p}=0.004)$, Mochhoury et al in $2013,{ }^{16}(\mathrm{p}=0.01)$, Li et al in $2013,{ }^{15}(\mathrm{p}<0.001)$, which showed significant associations between macrosomia and excess gestational weight gain. However, no significant association between EGWG and stillbirth was established, $(\mathrm{p}=0.365)$. 


\section{Conclusions and Recommendations}

Prevalence rate of excess gestational weight gain among women in Benue state is high and is strongly with Pregnancy Induced Hypertension, Preeclampsia, Caesarean Section in mothers and fetal macrosomia in the babies. These pregnancy outcomes increase cost of obstetrics care, length of stay in the hospital, morbidity and mortality for women, and as such, it should be controlled by ensuring that women gain the recommended weight before and during pregnancy. Likewise, macrosomia in neonates a public health issue is a risk factor for overweight or obesity at the beginning of childhood ${ }^{20}$. It also increases the risk of shoulder dystocia, brachial plexus, birth asphyxia, and in mothers, protracted labour, caesarean section, trauma to the birth canal, bladder, perineum, anal sphincter ${ }^{21}$ and postpartum hemorrhage. Findings from this study will create awareness in the society such that families, schools; civil society organizations, health care workers, will be encouraged campaign on gaining the right weight before and during pregnancy, which is key vital step to reduced negative pregnancy outcomes. From this study, it is paramount that measures should be put in place to prevent EGWG and this should be of great concern to the health care workers and the general population as such high EGWG prevalence, if unchecked will inadvertently lead to high maternal mortality ratio.

\section{Recommendations}

- Federal ministry of health should continue to coordinate with all health institution in the country on sensitizing the public of the benefits of initiating antenatal clinic visits within first eight weeks of gestation.

- Federal government through federal ministry of health should institute public health campaign targeting the society, hospitals, and traditional birth attendant (TBA) centers against gaining excess weight and the need to maintain appropriate pre-pregnancy weight.

- Women of childbearing age should be educated on the appropriate body mass index weight before and during pregnancy.

- Primary Health care institution should embark on routine community reproductive health services with the aim of detecting concerns requiring specialist attention.

- Women of childbearing age should make conscious effort to eat healthy foods before and during pregnancy.

- A prospective cohort study involving larger population should be conducted to further establish other adverse effect of excess gestational weight gain on pregnancy outcome.

\section{Appendix}

\section{Definition of Terms}

Caesarean Section (CS): A Caesarean section is a surgical procedure in which an incision is made through a mother's abdomen and uterus to deliver one or more babies.

Eclampsia: Eclampsia, a life-threatening complication of pregnancy, is defined as a condition that causes a pregnant woman, usually previously diagnosed with preeclampsia, to develop seizures or coma. 
Gestational Diabetes: Gestational diabetes is defined as any degree of glucose intolerance with onset or first recognition during pregnancy. This definition applies to whether insulin or only diet modification for treatment is used and whether diabetes mellitus persists after pregnancy.

Macrosomia: This is used to describe a newborn with excess birth weight of greater than $4000 \mathrm{~g}$. Preeclampsia: This is Pregnancy Induced Hypertension (PIH) which occurs after 20 weeks of gestation in conjunction with proteinuria (>300mg of protein in $24 \mathrm{hrs}$ urine sample).

Pregnancy Induced Hypertension (PIH): Pregnancy Induced Hypertension (PIH) is defined as having blood pressure of $140 / 90 \mathrm{mmHg}$ and above without the presence of protein in urine measured on two occasions at least four hours apart and diagnosed after 20 weeks of gestation. It must have developed for the first-time during pregnancy.

Stillbirth: This is defined as the delivery of a fetus without evidence of life after 28 weeks of gestation. The use of 28 weeks for this definition is for our environment as opposed to 20 weeks of gestation by World Health Organization and the United States National Center for Health Statistics.

\section{Acknowledgements}

To God, owner and giver of knowledge - Many thanks. To staff of department of community medicine, Nnamdi Azikiwe University, Benue University teaching hospital and Federal Medical Centre Makurdi, to Mum and siblings - we are grateful.

\section{References}

[1] Anzaku AS, Musa J. Prevalence and associated risk factors for gestational diabetes in Jos, Northcentral, Nigeria. Archives of Gynecology and Obstetrics. 2013 May;287(5);859-863.

[2] Singh S, Ahmed EB, Egondu SC, Ikechukwu NE. Hypertensive disorders in pregnancy among pregnant women in a Nigerian Teaching Hospital. Nigerian Medical Journal. 2014;55(5):384-388.

[3] Onoh RC, Eze JN, Ezeonu PO, Lawani LO, Iyoke CA, Nkwo PO. A 10-year appraisal of caesarean delivery and the associated fetal and maternal outcomes at a teaching hospital in southeast Nigeria. International Journal of Women's Health. 2015 May; 7:531-538.

[4] Onwuka CI, Ugwu EO, Onah HE, Obi SN, Onwuka CI, Menuba IE, et al. Patterns of gestational weight gain and its association with birth weight in Nigeria. Niger Journal of Clinical Practice. 2017;20(6):754-759.

[5] Mutihir JT, Eka PO. Stillbirths at the Jos University Teaching Hospital: incidence, risk, and etiological factors. Nigerian Journal of Clinical Practice. 2011;14(1);14- 18.

[6] Weight gain during pregnancy. Committee Opinion No. 548. American College of Obstetrics and Gynecologist. Journal of Obstetrics and Gynecology. 2013;121:210-212.

[7] Iyoke CA, Ugwu GO, Ezugwu FO, Lawani OL, Onyebuchi AK. Retrospective cohort study of the effects of obesity in early pregnancy on maternal weight gain and obstetric outcomes in an obstetric population in Africa. International Journal of Women's Health. 2013; 5: 501-504.

[8] Gilmore LA, Redman LM. Weight gain in pregnancy and application of the 2009 IOM guidelines: toward a uniform approach. Obesity (Silver Spring). 2015;23(3):507-511. 
[9] Halle-Ekane GE, Nsom BJ, Atashili J, Palle JN, Nsagha DS, Nguefack CT, et al. Outcome of Pregnancy in Women with Excessive Gestational Weight Gain in Two District Hospitals in Douala, Cameroon. SM Journal of Gynecology and Obstetrics. 2015; 1(1): 1-6.

[10] Fattah C, Farah N, Barry SC, O'Connor N, Stuart B, Turner MJ. Maternal weight and body composition in the first trimester of pregnancy. Acta Obstet Gynecol Scand 2010;89:952-955.

[11] Kirchengast S, Hartmann B. Determinants of gestational weight gain with special respect to maternal stature height and its consequences for newborn vital parameters. Anthropological Review. 2013; 76(2); 151-155.

[12] Must A, McKeown NM. The diease burden associated with overweight and obesity. Updated 2012 August 8. (accessed 2019 December 12). https://www.ncbi.nlm,nih,gov/books/NBK279095/

[13] Arora R, Arora D, Patumanond J. Risk of high gestational weight gain on adverse pregnancy outcome. Open Journal of Obstetrics and Gynecology. 2013;3:142-147.

[14] Zhou A, Xiong C, Hu R, Zhang Y, Bassig BA, Triche E, et al. Pre-Pregnancy BMI, gestational weight gain, and the risk of hypertensive disorders of pregnancy: A cohort study in Wuhan, China. PLoS ONE. 2015;10(8):1-7.

[15] Li N, Liu E, Guo J, Pan L, Li B. Maternal Prepregnancy Body Mass Index and Gestational Weight Gain on Pregnancy Outcomes. PLoS ONE. 2013;8(12):1-7.

[16] Mochhoury L, Razine R, Kasouati J, Kabiri M, Barkat A. Body Mass Index, Gestational Weight Gain, and Obstetric Complications in Moroccan Population. Journal of Pregnancy. 2013;2013(379461):1-5.

[17] Mbu RE, Fouedjio HJ, Tabot M, Fouelifack FY, Tumasang FN, Tonye RN, et al. Effects of gestational weight gain on the outcome of labour at the Yaounde central hospital maternity, Cameroon. Open Journal of Obstetrics and Gynecology. 2013;3:648-652.

[18] Chung JGY, Rennae ST, Thompson JMD, Anderson NH, Dekker GA, Kenny LC, et al. Gestational weight gain and adverse pregnancy outcomes in a nulliparous cohort. European Journal of Obstetrics and Gynecology and Reproductive Biology. 2012;7921:1-5.

[19] Hedderson MM, Gunderson EP, Ferrara A. Gestational Weight Gain and Risk of gestational diabetes mellitus. Obstetrics and Gynecology. 2010 Mar;115(3): 597- 604.

[20] Gu S, An X, Fang L, Zhang X, Zhang C, Wang J et al. Risk factors and long-term health consequences of macrosomia: a prospective study in Jiangsu Province, China. Journal of Biomedical Research. 2012;26(4):235-240.

[21] Campbell S. Fetal macrosomia: a problem in need of a policy. Ultrasound in /Obstetrics and Gynecology. 2014;43:3-10.

*Corresponding author.

E-mail address: celesmeka@yahoo.com 